\title{
Description on two species of genus Platythomisus (Araneae, Thomisidae) from China and Singapore
}

\author{
Yejie Lin', Joseph K.H. Koh², Lili Shao³, Shuqiang $\mathrm{Li}^{3}$ \\ I College of Life Science, Langfang Normal University, Langfang 065000, Hebei Province, China 2 National \\ Biodiversity Centre, National Parks Board, 259598, Singapore 3 Institute of Zoology, Chinese Academy of \\ Sciences, Beijing 100101, China \\ Corresponding author: Shuqiang Li (lisq@ioz.ac.cn)
}

Academic editor: A. Pérez-González | Received 11 March 2019 | Accepted 25 April 2019 | Published 5 June 2019

http://zoobank.org/8AFB6728-CAAC-463F-9E8A-A26BB2723B37

Citation: Lin Y, Koh JKH, Shao L, Li S (2019) Description on two species of genus Platythomisus (Araneae, Thomisidae) from China and Singapore. ZooKeys 852: 73-84. https://doi.org/10.3897/zookeys.852.34436

\begin{abstract}
Two species of the genus Platythomisus Doleschall, 1859 are studied: P. xiandao Lin \& Li, sp. nov. is described based on male and female specimens from Yunnan, China, and P. octomaculatus (C. L. Koch, 1845), the type species of the genus, is redescribed based on female specimens from Singapore. Its male, also from Singapore, is described for the first time.
\end{abstract}

\section{Keywords}

African region, new species, Oriental region, taxonomy, type species

\section{Introduction}

The spider genus Platythomisus Doleschall, 1859 includes 13 species, of which nine are known in the African region and four are distributed in the Oriental region, viz., P. jucundus Thorell, 1894 (Ô, Indonesia), P. octomaculatus (C. L. Koch, 1845) (ㅇ, Brunei, India, Indonesia, Malaysia, Singapore, Thailand), P. quadrimaculatus Hasselt, 1882 (juvenile, Indonesia), and P. sudeepi Biswas, 1977 ( ${ }^{\top}+$, India, Sri Lanka) (WSC 2019; Li and Quan 2017). 
We have since found matched pairs of two Platythomisus species in collections from Singapore and China. The discovery of one of these species, Platythomisus xiandao Lin \& Li sp. nov., from Yunnan represents the first record of this genus in China. Furthermore, specimens of P. octomaculatus (C. L. Koch, 1845) from Singapore have allowed us to provide the first description of the male of the species.

\section{Material and methods}

All specimens were preserved in $80 \%$ ethanol. Dissected genitalia were cleared in warm $10 \%$ potassium hydroxide $(\mathrm{KOH})$ solution before study. Specimens were examined under a LEICA M205C stereomicroscope. Photomicroscopy images were taken with an Olympus C7070 zoom digital camera (7.1 megapixels). Laboratory habitus photographs were taken with a Canon 5D Mark III digital camera equipped with a Canon MP-E 65 mm lens. Photos were stacked with Helicon Focus (version 6.7.1) or Zerene Stacker (version 1.04) and processed in Adobe Photoshop CC2018. Field photographs were taken with a Nikon D800E with a Tamron $90 \mathrm{~mm}$ macro lens.

All measurements are in millimeters and were obtained with a LEICA M205C stereomicroscope. Eye sizes are measured as the maximum diameter from either the dorsal or frontal view. Leg measurements are given as follows: total length (femur, patella, tibia, metatarsus, tarsus). The terminology used in the text and figures follows Ono (1988). Distribution maps were generated using ArcMap software (version 10.2).

The types of Platythomisus xiandao Lin \& Li, sp. nov. are deposited at the Institute of Zoology, Chinese Academy of Sciences in Beijing (IZCAS). The voucher specimens of $P$. octomaculatus of this study are kept at the Lee Kong Chian Natural History Museum, National University of Singapore (LKCNHM).

To confirm the species delimitation, a fragment of the cytochrome c oxidase subunit I (COI) was amplified and sequenced. Primer sets for the PCR and cycle sequencing reactions in this study are from Folmer et al. (1994). The GenBank accession numbers are provided in Table 1. MEGA7.0.16 (Kumar et al. 2016) was used for subsequent manual adjustment of the sequences and calculation of pairwise comparisons of uncorrected K2P-distances. COI sequences of Thomisus Walckenaer, 1805 were also obtained from GenBank to calculate intraspecific genetic distance.

Abbreviations: ALE anterior lateral eyes, AME anterior median eyes, PLE posterior lateral eyes, PME posterior median eyes, E embolus, ITA intermediate tibial apophysis, RTA retrolateral tibial apophysis, VTA ventral tibial apophysis, At atrium, CD copulatory duct, $\mathbf{S}$ spermathecae.

Table I. The accession numbers for two species in this paper.

\begin{tabular}{lcc}
\hline \multicolumn{1}{c}{ Species } & Length (bp) & GenBank accession number \\
\hline Platythomisus octomaculatus & $647 \mathrm{bp}$ & MK774520 \\
Platythomisus xiandao sp. nov. & $647 \mathrm{bp}$ & MK774521 \\
\hline
\end{tabular}




\section{Taxonomy}

\section{Family Thomisidae Sundevall, 1833 \\ Subfamily Thomisinae Sundevall, 1833}

\section{Genus Platythomisus Doleschall, 1859}

Type species. Thomisus 8-maculatus C.L. Koch, 1845, from Ostindien.

Diagnosis. Sexual dimorphism is distinct in Platythomisus. Females can be easily distinguished from most other thomisids by their extraordinary large size [up to $20 \mathrm{~mm}$ in length in some specimens of the type species P. octomaculatus (C. L. Koch, 1845)] with strikingly contrasting color patterns on the carapace and opisthosoma. Typically, the epigyne has sclerotized margins and a conspicuous epigynal atrium; spermathecae longer than wide, well-sclerotized, and not divided into compartments. The male is much smaller than female (1:3 or more). Palp with VTA, ITA and RTA; tegulum flat, disk-shaped; tegular ridge present; embolus slender.

Distribution. Oriental and African zoogeographic regions.

\section{Platythomisus octomaculatus (C. L. Koch, 1845)}

Figs 1A-C, 2A, C, 3A, B, 4A-D, 5A, B, 6

Thomisus 8-maculatus C.L. Koch 1845: 55, fig. 990 ()).

Platythomisus phryniformis Doleschall 1859: 60 pl. 3, fig. 10 (†).

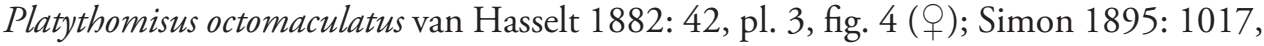
fig. 1076 (ㅇ).

Type material. The holotype of $P$. octomaculatus was not examined as it could not be located in any of the databases of all the major museums in Europe.

Specimens examined. $\widehat{\partial}$ (LKCNHM), Singapore, Pasir Ris Road, Pasir Ris Nature Park, mangrove foliage, 09.X.2018, J. Koh leg.; ㅇ (LKCNHM), Singapore, Neo Tiew Crescent, Sungei Buloh Wetland Reserve, mangrove foliage, 01 ${ }^{\circ} 26^{\prime} 49^{\prime \prime N}$, $103^{\circ} 43^{\prime} 45^{\prime \prime E}$, 20.IV.2016, M. Tan leg. ㅇ (LKCNHM), Singapore, Neo Tiew Crescent, Sungei Buloh Wetland Reserve, mangrove foliage, 01²6'53"N, 10343'42"E, 13.I.2013, J. Koh leg.

Diagnosis. See diagnosis of the species Platythomisus xiandao sp. nov.

Description. Male (Figs 1A-C, 2A, C, 4C, D, 5B): total length 3.72, carapace 1.62 long, 1.5 wide, opisthosoma 2.18 long, 1.52 wide. Carapace reddish brown. Eye region orange, AER and PER recurved. Eye sizes and interdistances: AME 0.06, ALE 0.09, PME 0.04, PLE 0.08, AME-AME 0.26, AME-ALE 0.20, PME-PME 0.37, PME-PLE 0.28, AME-PME 0.17, ALE-PLE 0.19. Clypeus 0.13 high, red. Chelicerae red, with ridge, without any teeth. Endites and labium red anteriorly and black posteriorly. Sternum black, with sparse hairs. Legs white, coxae faint black, 


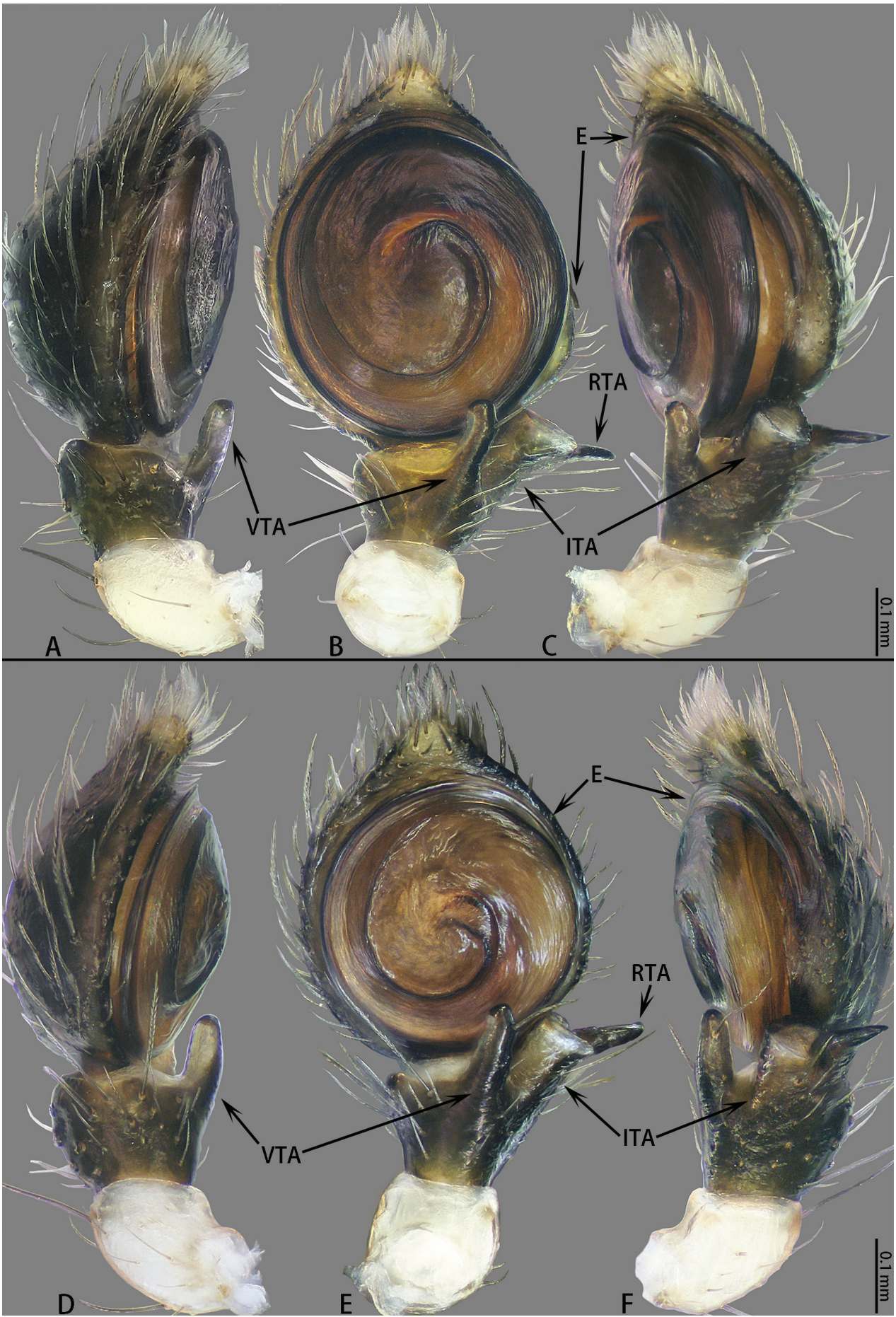

Figure I. Male palps of Platythomisus octomaculatus (C. L. Koch, 1845) (A, B, C) and Platythomisus xiandao sp. nov. (D, E, F). A Left, prolateral view B Same, ventral view C Same, retrolateral view D Right male palp (Horizontal flip), prolateral view E Same, ventral view F Same, retrolateral view. 


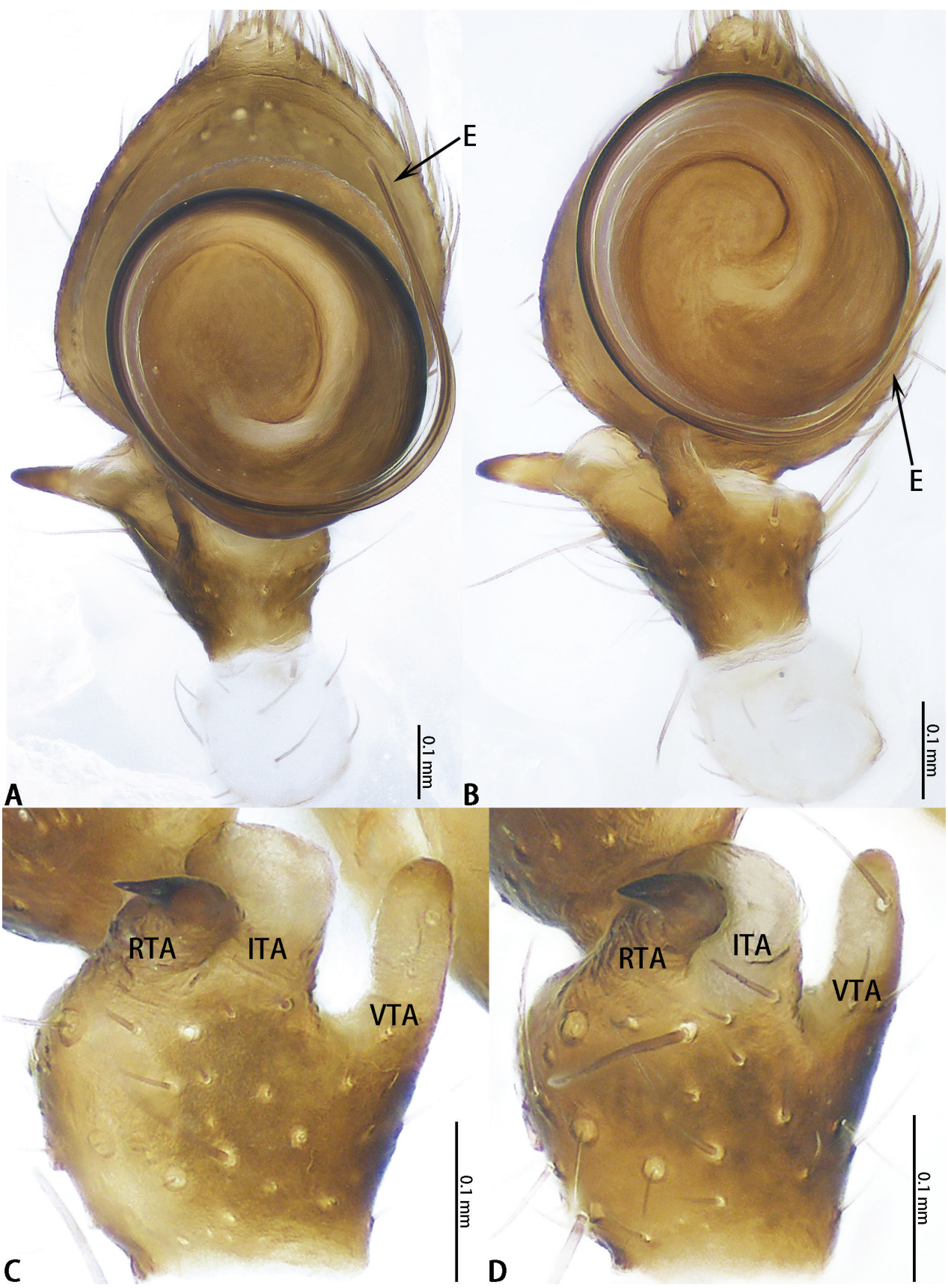

Figure 2. Expanded male palps (treated with $10 \% \mathrm{KOH}$ ) of Platythomisus octomaculatus (C. L. Koch, 1845) (A, C) and Platythomisus xiandao sp. nov. (B, D). A, B Right, ventral view C, D Same, tarsus apophysis retrolateral view. 
tarsi, metatarsi and tibiae have a longitudinal black line dorsally each. Legs translucent when alive. Leg I: $6.45(2.05+2.26+1.23+0.91)$, leg II: $6.60(2.18+2.35+$ $1.19+0.88)$, leg III: $3.84(1.34+1.44+0.54+0.52)$, leg IV: $3.56(1.31+1.30+$ $0.46+0.49)$. Leg formula: 2134 . Opisthosoma broadly pentagonal, dorsum yellowcinnamon, ventrum reddish-brown. Dorsum with three distinct black spots and four smaller faint brown spots, with red folds laterally, ventrum with a large shield-shaped black patch. Spinnerets black.

Male palp (Figs 1A-C, 2A, C). Femur white. Tibia black, VTA club-shaped, with a thick bristle near the apex. ITA boot-shaped, terminally flat with a laterally pointing extension. RTA long, terminal slightly bent. Cymbium black. Tegulum flat, diskshaped, with a tegular ridge. Embolus spiral, thin, the base of embolus arising from a 1:30-o'clock-position, the length of embolus to the length of embolus base 5:1 (Fig. 2A).

Female (Figs 3A, B, 4A, B, 5A) markedly larger and different from male. Total length 17.05, carapace 8.21 long, 7.63 wide, opisthosoma 10.00 long, 7.31 wide. Carapace yellow with three pairs of black spots. The anterior pair cover the ALE and PLE, adjacent to AME and PME; middle spots extremely small. AER and PER slightly recurved. Eye sizes and interdistances: AME 0.14, ALE 0.19, PME 0.10, PLE 0.16, AME-AME 1.14, AME-ALE 0.93, PME-PME 1.61, PME-PLE 1.01, AME-PME 0.54, ALE-PLE 0.42. Clypeus height 0.68, orange. Chelicerae orange, with ridge, margin has a thin brown ring pattern, without any teeth. Endites and labium orange. Sternum orange, with sparsely set hairs. Legs two-colored, with coxa, trochanter, femur and patella in orange, and metatarsus and tarsus black. Coloration of the tibiae varies: black in tibiae I and II, while orange in tibiae III and IV. Leg I: $26.84(8.14+9.62+$ $6.02+3.06)$, leg II: $27.24(8.21+9.94+6.09+3.00)$, leg III: $15.64(5.58+5.90+$ $2.50+1.66)$, leg IV: $15.81(5.32+6.47+2.47+1.55)$. Leg formula: 2143 . Opisthosoma sub-rectangular with a bluntly pointed posterior end, yellow, laterally pleated. Dorsum with seven blue-grey spots, ventrum with an oblong black patch. Spinnerets black, surrounded by a narrow black ring.

Epigyne (Figs 3A, B) with atrium shaped like a funnel with a broad neck, the length of atrium to the middle width of the atrium $1: 1.5$, the length of anterior margin to the length of posterior margin 2:1. CD short, approximately half the length of the spermathecae. Spermathecae stout, with almost parallel sides anteriorly.

Intraspecific variations: While the holotype has eight spots on the dorsum, as illustrated by Koch (1845), mature specimens seen or photographed in Singapore, Brunei, Thailand, and East and West Malaysia possess only seven dorsal spots but with the eighth spot on the ventrum. In some juvenile females, there are only five dorsal spots on the opisthosoma. The number of spots on the carapace varies between two and four pairs in mature females. The general coloration of live male specimens varies from yellow to red.

Distribution. The type locality "Ostindien”, meaning "East Indies”, refers to Indonesia today. Within Indonesia, the species was recorded in Java as Platythomisus phryniformis by Doleschall (1859) and in Padang, Sumatra by Hasselt (1882). However, we failed to find any specimens of the species during field trips in the country. This 
species has been recorded in Singapore, Brunei, Thailand, and East and West Malaysia (Koh and Leong 2014). A report of P. octomaculatus from Assam, India (Yadav et al. 2017) is clearly misidentified. We suggest it may be $P$. xiandao sp. nov.

Natural history. Individuals live among low-lying tree foliage in or around degraded forests and mangrove swamps. Eggs are laid between leaves and sealed with thick silk. The egg sacs are guarded by the mother until the spiderlings hatch in about 2 weeks.

\section{Platythomisus xiandao sp. nov.}

http://zoobank.org/E45077FE-3209-4887-AD5A-A7DA989FC2FF

Figs $1 \mathrm{~B}-\mathrm{D}, 2 \mathrm{~B}, \mathrm{D}, 3 \mathrm{C}, \mathrm{D}, 4 \mathrm{E}-\mathrm{H}, 5 \mathrm{C}, \mathrm{D}, 6$

Holotype. $\widehat{\jmath}$ (IZCAS), China, Yunnan Prov., Jinghong City, Mount Jinuo, hatched from paratype egg sac. Hatched 12.X.2017, matured 10.IV.2018, C.T. Wei leg. Paratype: + (IZCAS), same locality data as holotype, collected 06.X.2017, C.T. Wei leg.

Etymology. The specific name is derived from the Chinese word "xiandao" (noun), the name of the Strategic Priority Research Program of the Chinese Academy of Sciences (CAS). The program has made it possible for the biodiversity research team in the CAS to remain as an integral cluster to fulfil all its ambitious goals.

Diagnosis. Male of $P$. xiandao sp. nov. can be easily distinguished from that of $P$. octomaculatus by the length of embolus to the length of embolus base is $3: 1$ (Fig. 2B), but 5:1 in P. octomaculatus (Fig. 2A), the base of embolus arising from a 3:30-o'clockposition in P. xiandao sp. nov. (Fig. 1E), and 1:30-o'clock-position in P. octomaculatus (Fig. 1B); the atrium of P. xiandao sp. nov. is bell-shaped (Fig. 3C) while that of P. octomaculatus is funnel-shaped (Fig. 3A); the spermathecae of P. xiandao sp. nov. (Fig. 3D) are more slender than those in P. octomaculatus (Fig. 3B).

The two species can also be diagnosed by their somatic differences. The males of P. xiandao sp. nov. have seven black spots on the opisthosoma (Fig. 4G) and a reddish sternum (Fig. 4H); the males of P. octomaculatus have only three distinct black spots on the opisthosoma (Fig. 4C) and a black sternum (Fig. 4D). The females of P. xiandao sp. nov. have larger black patches on the carapace (Fig. 4A) and a black patch at the center of ventrum extending posteriorly to connect with the black area surrounding the spinnerets through a narrow neck (Fig. 4F), while the black patch at the ventrum of $P$. octomaculatus females is broadly oblong and well-separated from the spinnerets (Fig. 4B).

Description. Male (Figs 1D-F, 2B, D, 4G, H, 5D): total length 3.92, carapace 1.55 long, 1.38 wide, opisthosoma 2.40 long, 1.70 wide. Carapace red. Eye region orange, AER and PER recurved. Eye sizes and interdistances: AME 0.05, ALE 0.09, PME 0.03, PLE 0.06, AME-AME 0.24, AME-ALE 0.17, PME-PME 0.32, PMEPLE 0.28, AME-PME 0.13, ALE-PLE 0.19. Clypeus 0.13 high, red. Chelicerae red, with ridge, without any teeth. Endites and labium red. Sternum red, sparsely set hairs. Legs white, coxa black, tarsus, metatarsus, tibia, patella and femur of leg I and II have two black lines. Legs transparent when alive. Leg I: $5.73(1.86+2.00+1.08+0.79)$, leg II: $6.04(2.02+2.10+1.10+0.82)$, leg III: $3.20(1.00+1.20+0.51+0.49)$, leg 


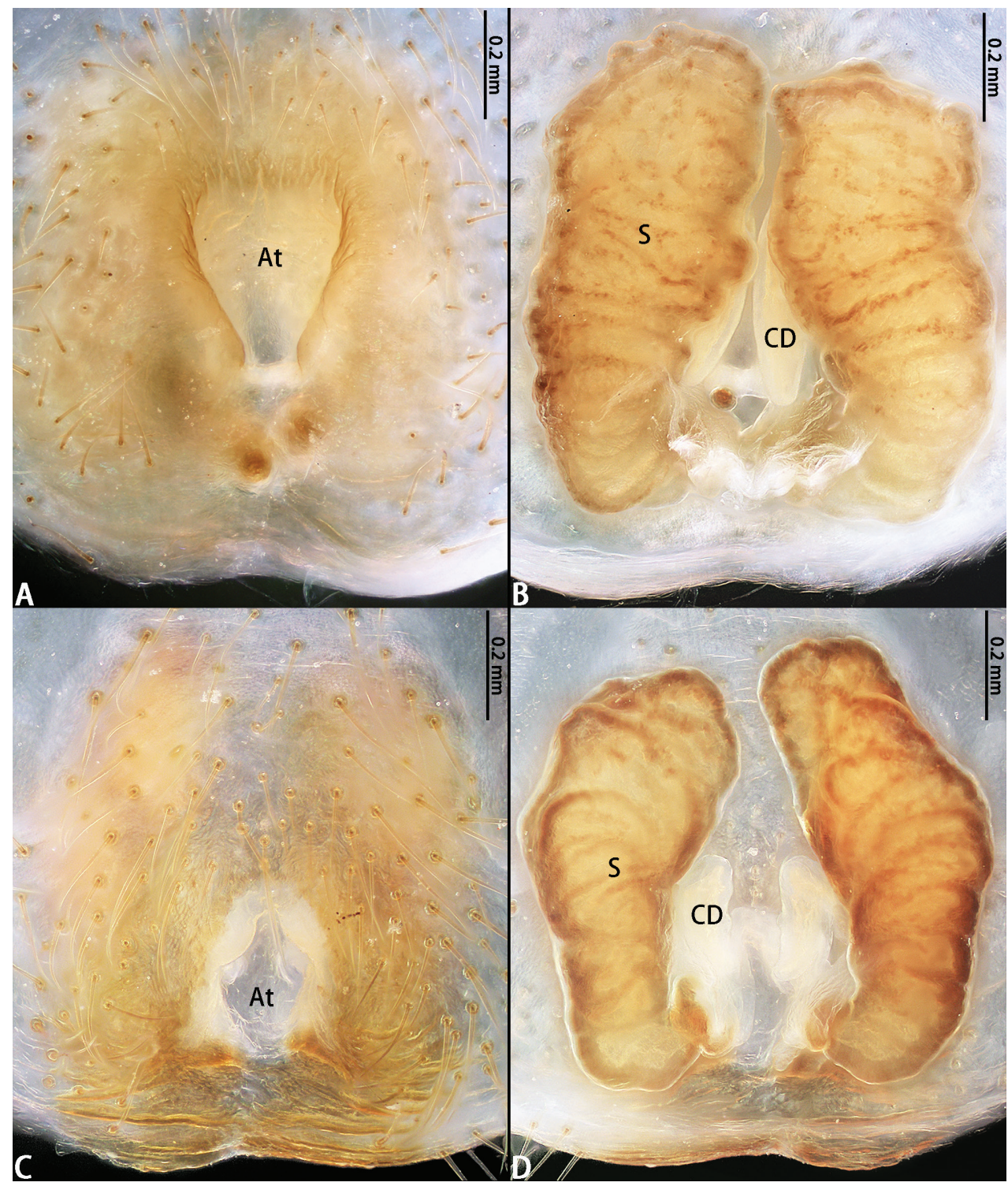

Figure 3. Epigyna and vulvae of Platythomisus octomaculatus (C. L. Koch, 1845) (A, B) and Platythomisus xiandao sp. nov. (C, D). A, C Epigyne, ventral view B, D Vulva, dorsal view.

IV: $3.27(1.21+1.11+0.46+0.49)$. Leg formula: 2143 . Opisthosoma oval, white, dorsum cinnamon, ventrum reddish-brown. Opisthosoma dorsum with seven black spots, first one largest, lateral sides with red folds, ventrum reddish-brown, with a large shield-shaped black pattern. Spinnerets black.

Male palp (Figs 1D-F, 2B, D). Femur white. Tibia black, VTA club-shaped, slightly bent, with a bristle near the apex. ITA boot-shaped, terminally flat with lateral exten- 


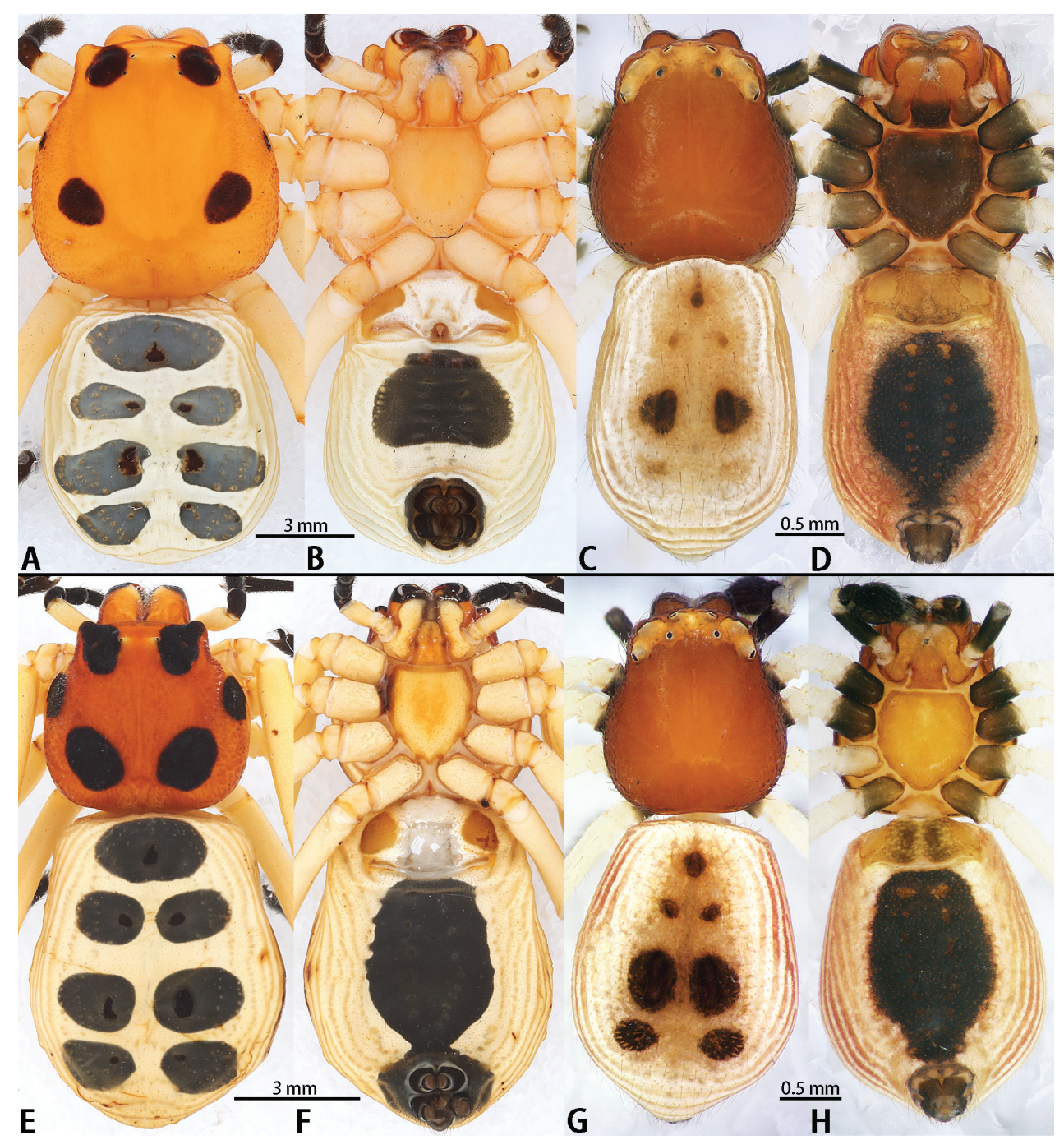

Figure 4. Habitus of Platythomisus octomaculatus (C. L. Koch, 1845) (A-D) and Platythomisus xiandao sp. nov. (E-H). A, E Female habitus, dorsal view B, F Female habitus, ventral view C, G Male habitus, dorsal view; $\mathbf{D}, \mathbf{H}$ Male habitus, ventral view.

sion. RTA long and thin, terminal slightly bent. Cymbium black. Tegulum flat, diskshaped, with tegular ridge. Embolus slender and spiral, the base of embolus arising from a 3:30-o'clock-position, the length of embolus to the length of embolus base 3:1 (Fig. 2B).

Female (Figs 3C, D, 4E, F, 5C) distinctly different from male. Total length 13.01, carapace 5.20 long, 5.05 wide, opisthosoma 8.78 long, 6.35 wide. Carapace yellow with three pairs of big black subcircular patches. The anterior pair extend to the protruding ends on both lateral sides of the ocular tubercles, covering the ALE, PME and PLE, and adjoining the AME. The median pair of black disks smaller than the 


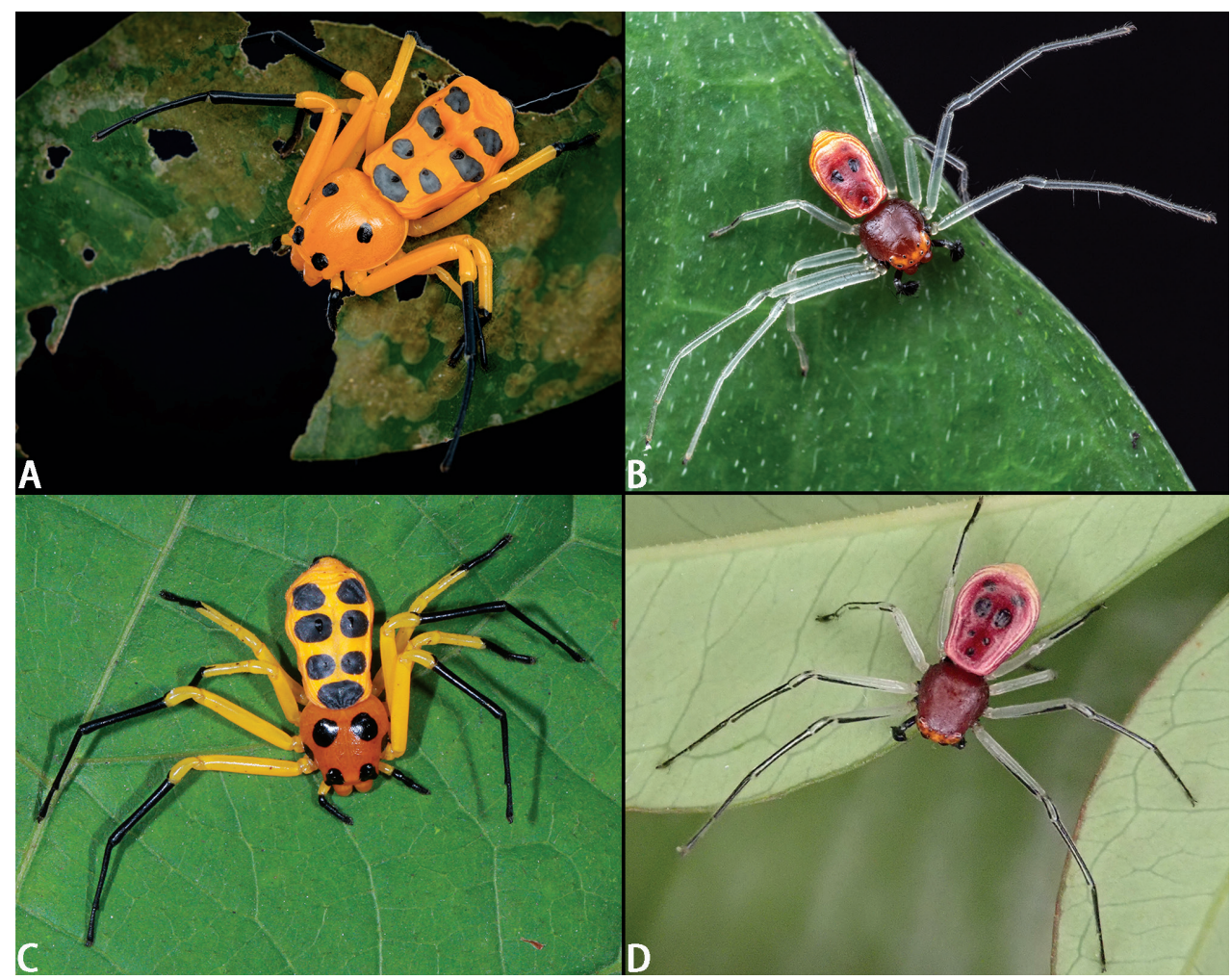

Figure 5. Photos of alive Platythomisus octomaculatus (C. L. Koch, 1845) (A, B) and Platythomisus xiandao sp. nov. (C, D) A, C Female B, D Male.

anterior and posterior pairs. AER and PER slightly recurved. Eye sizes and interdistances: AME 0.11, ALE 0.12, PME 0.05, PLE 0.09, AME-AME 0.81, AME-ALE 0.54, PME-PME 1.02, PME-PLE 0.71, AME-PME 0.37, ALE-PLE 0.36. Clypeus height 0.56 , orange. Chelicerae orange, with ridge, margin has a black ring pattern, without any teeth. Endites and labium orange. Sternum orange, sparsely set hairs. Legs bicolored, coxa, trochanter, the femur of leg I and II black, the patella of leg I and II and the femur of leg III and IV orange with a black inverted triangle spot. Other legs orange. Leg I: $18.09(5.70+6.41+3.96+2.02)$, leg II: $18.54(5.96+$ $6.54+4.00+2.04), \operatorname{leg}$ III: $10.82(3.64+4.04+1.88+1.26)$, leg IV: $11.16(3.92+$ $4.35+1.66+1.23)$. Leg formula: 2143 . Opisthosoma pentagonal, yellow. Opisthosoma dorsum with seven black spots, with the largest in the anteriormost spot, lateral folded, ventrum yellow, with a shield-shaped black pattern coalescing with the black ring surrounding the black spinnerets.

Epigyne (Fig. 3C, D) with bell-shaped atrium, the length of atrium to the middle width of the atrium 1:1.4, the length of anterior margin to the length of posterior margin 1:1. CD short, about one-fourth the length of the spermathecae. Spermathecae comparatively slender, shaped like a sea cucumber or hot-dog sausage.

Distribution. China (Yunnan). 


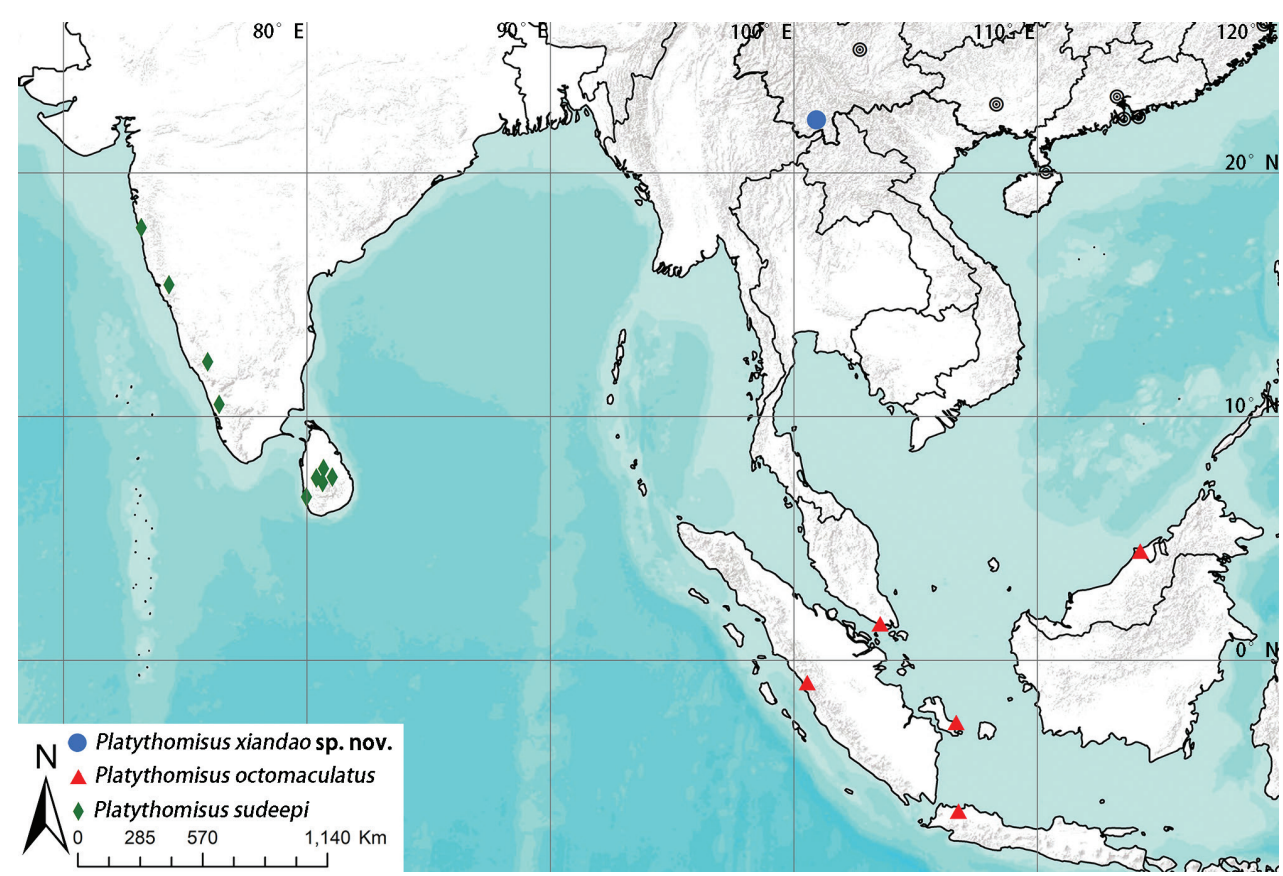

Figure 6. Known distribution of Platythomisus species in Oriental Region.

Natural history. Individuals of this species hide under the leaves.

Remarks. Based on the 647 bp-aligned sequences, the COI uncorrected K2P-distance between $P$. octomaculatus and $P$. xiandao sp. nov. is 0.073 . The result far exceeded the maximum value of intraspecific genetic distance for Thomisidae.

\section{Acknowledgements}

The manuscript benefitted greatly from comments by Abel Pérez-González, Hirotsugu Ono, Yuri Marusik, André Wanderley do Prado, and Suresh Benjamin. Jishen Wang and Hotaru Amamiya suggested the name of the new species. Paul Y.C. Ng contributed the image of a live male P. octomaculatus, Guiqiang Huang and Xuankong Jiang helped with the images of live $P$. xiandao sp. nov. Zhengzhong Huang provided the habitus images of preserved female specimens of both species. This study was supported by the National Natural Science Foundation of China (NSFC-31530067) to Shuqiang Li.

\section{References}

Benjamin SP, Ileperuma Arachchi IS, Herath BP (2016) First record of Platythomisus sudeepi from Sri Lanka (Araneae: Thomisidae). Arachnology 17(3): 165-168. https://doi.org/10.13156/ arac.2006.17.3.165 
Doleschall L (1859) Tweede Bijdrage tot de kennis der Arachniden van den Indischen Archipel. Acta Societatis Scientiarum Indica-Neerlandica 5: 1-60.

Folmer O, Black M, Hoeh W, Lutz R, Vrijenhoek R (1994) DNA primers for amplification of mitochondrial cytochrome $\mathrm{c}$ oxidase subunit I from diverse metazoan invertebrates. Molecular Marine Biology \& Biotechnology 3: 294-299.

Hasselt AWM van (1882) Araneae. In: Veth PJ (Ed.) Midden-Sumatra 4A (11). Reizen en onderzoekingen der Sumatra-expeditie, uitgerust door het aardrijkskundig genootschap, 1877-1879. Brill, Leiden, 1-56. https://doi.org/10.5962/bhl.title.119451

Koch CL (1845) Die Arachniden. Zwölfter Band 1. C. H. Zeh`sche Buchhandlung, Nürnberg, $166 \mathrm{pp}$.

Koh JKH, Leong TM (2014) Spiders of Borneo. Opus Publications, Kota Kinabalu, 357 pp.

Kumar S, Stecher G, Tamura K (2016) MEGA7: Molecular Evolutionary Genetics Analysis version 7.0 for bigger datasets. Molecular Biology and Evolution 33(7): 1870-1874. https://doi.org/10.1093/molbev/msw054

Li S, Quan R (2017) Taxonomy is the cornerstone of biodiversity conservation - SEABRI reports on biological surveys in Southeast Asia. Zoological Research 38(5): 213-214. https:// doi.org/10.24272/j.issn.2095-8137.2017.061

Ono H (1988) A Revisional Study of the Spider Family Thomisidae (Arachnida, Araneae) of Japan. National Science Museum, Tokyo, 252 pp.

WSC (2019) World Spider Catalog, version 20.0. Natural History Museum, Bern. https://doi. org/10.24436/2 [2019-3-8]

Yadav S, Patil V, Ismavel VA (2017) Report of Platythomisus octomaculatus (C. L. Koch, 1845) and Platythomisus sudeepi Biswas, 1977 from India (Araneae, Thomisidae). Biodiversity Data Journal 5: e10294. https://doi.org/10.3897/BDJ.5.e10294 